\title{
Role of MRI in Ano-rectal Fistulas
}

\author{
Anagha R. Joshi $\cdot$ Sukhvinder G. Siledar
}

Published online: 3 August 2014

(C) Springer Science+Business Media New York 2014

\begin{abstract}
Perianal fistulae are a relatively common condition. They are thought to be a result of anal gland obstruction, with secondary abscess formation and external rupture of the abscess. They have traditionally been imaged by conventional fistulograms: transrectal ultrasound and CT scan. However, each of these procedures had its own disadvantages \& limitations. Until the recent past, magnetic resonance (MR) imaging had a limited role in the preoperative assessment of perianal fistulas, though the role of MR imaging has been shown to demonstrate accurately the anatomy of the perianal region. In addition to showing the anal sphincter mechanism, MR imaging clearly shows the relationship of fistulas to the pelvic diaphragm (levator plate) and the ischiorectal fossae. This relationship has important implications for surgical management.
\end{abstract}

Keywords MRI - Ano-rectal fistulas · Perianal fistulae · Surgical management

\section{Introduction}

'Fistula' is the Latin word for a reed, pipe, or flute. In medicine, it implies a chronic granulating track connecting two epithelium lined surfaces. These surfaces may be cutaneous or mucosal. Perianal fistulas run from the anal

This article is part of Topical Collection on Abdominal CT Imaging.

A. R. Joshi

LTMMC \& LTMGH, Sion, Mumbai, India

e-mail: anaghaj@gmail.com

S. G. Siledar $(\bowtie)$

Government Cancer Hospital, Aurangabad, India

e-mail: siledarsukhvinder@gmail.com canal to the perianal skin or perineum. Perianal fistulas are not uncommon, with a prevalence of $0.01-0.05 \%$, and are associated with considerable discomfort and morbidity to the patient.

The first treatise regarding the treatment of perianal fistulas was probably written by Hippocrates of Cos (460 $\mathrm{BC}-370 \mathrm{BC}$ ). Although perianal fistulas have been described throughout centuries, they began to receive special attention in the nineteenth century. Much work on perianal fistulas was done at the St. Mark's hospital, London by surgeons such as Salmon, Goodsall, and Parks. Goodsall described the famous Goodsall rule [1] to judge the position of internal opening, and Parks published the classification of fistulas [2•] which is widely known and used.

Although fistula seems to be a simple disease, both the disease and its improper surgical treatment can cause significant morbidity. Hence, it is of utmost importance that as much information be available about the disease in a patient as possible prior to the surgery, else treatment failure or recurrence is inevitable. Prior to the introduction of radiological imaging, management of patients with perianal fistula included clinical examination of the perianal region and per rectal examination to know the approximate course of the tract and the presence or absence of internal opening and its location. Further, adages like the Goodsall's rule were taken into account. However, it was impossible to differentiate between a fistula and a sinus, to know about exact location of internal opening of the fistula, any branching of the fistulous tract, associated collections, and associated inflammatory disease of the rectum if any. Treatment included simply laying open the fistulous tract i.e., fistulotomy. The other method of treatment was the 'seton' technique [3], which also has been described in the Ayurveda by Sushruta (termed as 'Ksharsutra'). 
However, even with meticulous clinical examination and seemingly adequate surgery, there was significantly high rate of recurrence. The need for revision of the diagnostic methods and treatment planning was felt with the increasing knowledge of inadequate treatment response in most patients. Hence, radiological imaging was introduced in the management of perianal fistulas. Few of the causes thought for the recurrence were incomplete removal of the fistulous tract, persistent infection/inflammation, and associated inflammatory disease of the rectum and colon. Thus began the use of radiology in management of perianal fistulas, with the use of imaging modalities available at that time i.e., fistulography and if required barium enema examinations.

However, with time, the limitations of these modalities were realized. Ultrasonography also was introduced as to overcome the limitations of conventional diagnostic methods. Still, in most cases, these modalities could not provide all the information that were required, and there were recurrences. The advent of MRI, with its superior soft-tissue contrast resolution and multiplanar imaging capabilities, brought a dramatic change in imaging of perianal fistulas. Surgical procedures after MRI have showed significantly better results. Still, MRI for perianal fistulas has yet to gain wider acceptance. Numerous studies have been done comparing the efficacy of MRI with the other imaging modalities available. Much work has also been done on refining the MRI protocol for evaluating perianal fistulas from the use of endorectal coils to the use of newer and advanced sequences. The use of MRI in perianal fistulas is continuously evolving.

However, with more advancement, comes greater responsibility. With the availability of advanced technology, there are not only more choices and better performance but also greater expectations. The availability of these options, each with its own pros and cons, has made it necessary to identify the best modality in general and for each patient so as to be able to answer important questions the presence or absence of fistula, its course and relations, exact location of the internal opening, associated inflammatory conditions like abscesses or collections, and any other relevant information that can help patient management. It is the duty of the radiologist to choose the imaging modality which would give the maximum relevant information in any given case, to choose the most cost-effective imaging modality, and to always comply with the principle of As Low As Reasonably Achievable (ALARA) if the workup of a patient requires exposure to radiation. Patients should not be subjected to unnecessary investigations which do not provide much diagnostic information. In case of MRI, every radiologist must be familiar with its role in evaluating perianal fistulas, and its pros and cons as compared to other methods.

\section{Relevant Anatomy}

The anal canal extends from the anus to the rectal ampulla and is $2-5 \mathrm{~cm}$ in length, and shorter in women than in men. The anal canal is a cylindrical structure surrounded by two muscular layers, the internal and external sphincters.

\section{The Internal Sphincter}

It is composed of smooth muscle, the fibers of which are continuous with the circular smooth muscle of the rectum. This sphincter contracts involuntarily and is responsible for $85 \%$ of the resting tone of the anal canal [ $4 \cdot \bullet$ ].

The longitudinal muscle is formed by distal termination of rectal longitudinal smooth muscle and does not clearly contribute to the function of the anal sphincter.

\section{The External Sphincter}

It is composed of striated muscle and has posterior attachments to the anococcygeal ligament and anterior attachments to the perineal body and urogenital diaphragm. It merges proximally with the puborectalis muscle, which then merges with the levator plate of the pelvic floor. The puborectalis is the lowermost part of the funnel-shaped levator ani muscles, which separate the perineum from the pelvic cavity. The external sphincter contributes only $15 \%$ of the resting anal tone, although its strong voluntary contractions prevent defecation [4*0].

The internal sphincter can be divided without causing loss of continence, but excessive division of the external sphincter can lead to fecal incontinence.

\section{Intersphincteric Space}

The two sphincters are separated by the intersphincteric space, which contains fat, areolar tissue, and the longitudinal muscle. This space forms a natural plane of lower resistance in which fistulas and pus can readily spread.

\section{Anal Canal Lining}

In terms of the lining of the anal canal, somatic skin should theoretically reach the anal margin, but in fact it advances up to a point approximately halfway along the anal canal. Here, squamous epithelium gives way to columnar epithelium, often through a transition zone. The proximal half of the anal canal is characterized by longitudinal mucosal folds, the anal columns of Morgagni. The distal part of each column is linked to its neighbors by small semilunar folds, the anal valves, which in turn form small pockets, the crypts of Morgagni. The undulating distal limit of these valves is known as the dentate line (pectinate line), which 
marks the most distal region of the anal transition zone, approximately $2 \mathrm{~cm}$ proximal to the anal verge. At the dentate line, the epithelium becomes transitional: this anal transition zone with modified columnar epithelium has a high sensory enervation important for continence and normal defecation.

\section{The Anal Glands}

First described by Chiari in 1878, they are six to 10 branched glandular structures with a stratified columnar epithelium lining. These glands are evenly distributed around the circumference of the anal canal, with ducts opening into the base of the crypts of Morgagni, located above the anal valves at the level of the dentate line. In most of the population, these glands are subepithelial (submucosal), but some branches may pass through the internal sphincter to end in the areolar tissue of the intersphincteric space. Branches of any gland may extend over an area of about $1 \mathrm{~cm}^{2}$, but as a general rule, the anal glands do not extend out into the external sphincter. Anal glands provide a free channel facilitating the spread of infection from the anal lumen deep into the sphincter muscles, from where it may spread secondarily in almost any direction (Figs. 1, 2, 3, 4, 5, 6).

\section{Etiology and Pathophysiology}

Perianal fistulas may be caused by several inflammatory conditions and events, including Crohn's disease, pelvic infection, tuberculosis, diverticulitis, trauma during childbirth, pelvic malignancy, and radiation therapy. However,

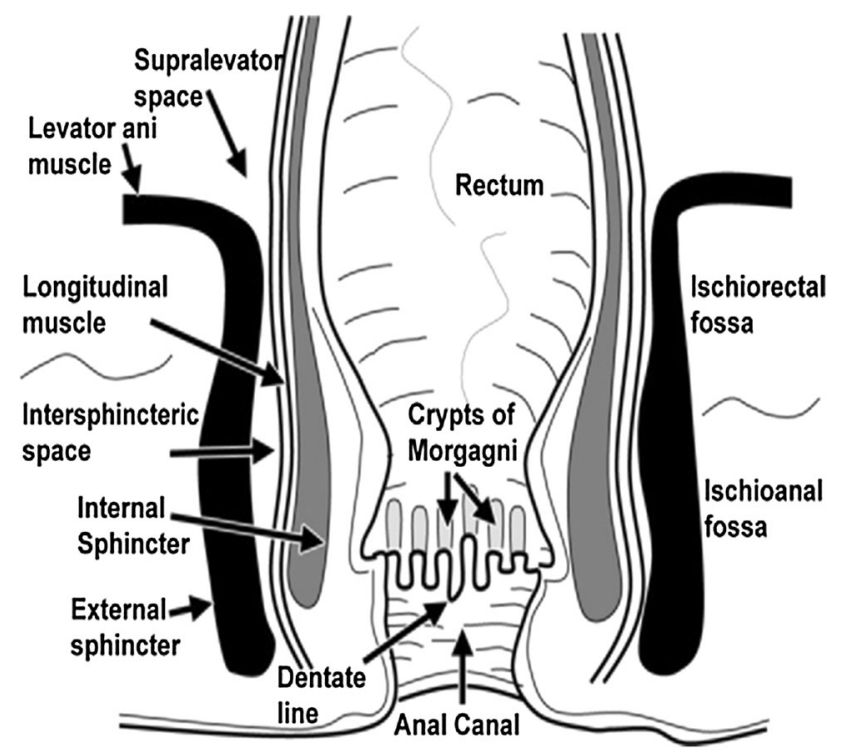

Fig. 1 Diagrammatic representation to demonstrate normal anatomy in a coronal section $\left[4{ }^{\bullet} \cdot\right]$ most are idiopathic and are generally thought to represent the chronic phase of intramuscular anal gland sepsis. Perhaps, the most widespread theory about the cause of perianal fistula is the "Cryptoglandular hypothesis," whereby intersphincteric gland infection represents the initial event, which leads to the formation of an intersphincteric fistula track or abscess if the draining duct becomes obstructed. Chronic infection in the primary site in the intersphincteric plane produces a persistently discharging fistula or recurrent abscess.

Most of the glands are subepithelial, with some lying in the longitudinal layer deep in the internal sphincter, although others may terminate in the intersphincteric space, close to the external sphincter. If an abscess develops in a superficial gland, then it is most likely to discharge spontaneously into the anal canal. However, if the abscess is located deep to the internal sphincter, then the sphincter can act as a barrier. In such cases, rupture of the abscess results in pus traveling along the path of least resistance,

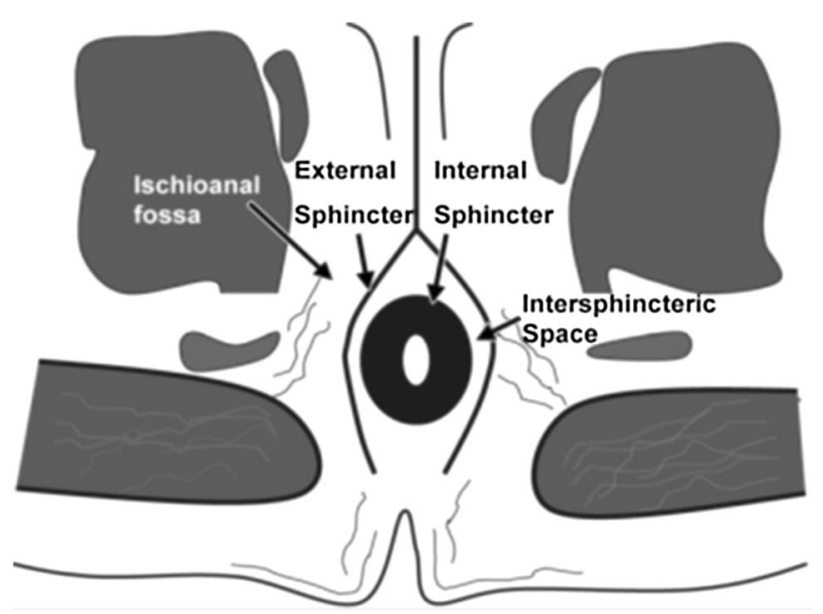

Fig. 2 Diagrammatic representation demonstrating normal male perianal anatomy in axial plane at the level of ischiorectal fossae [4••]

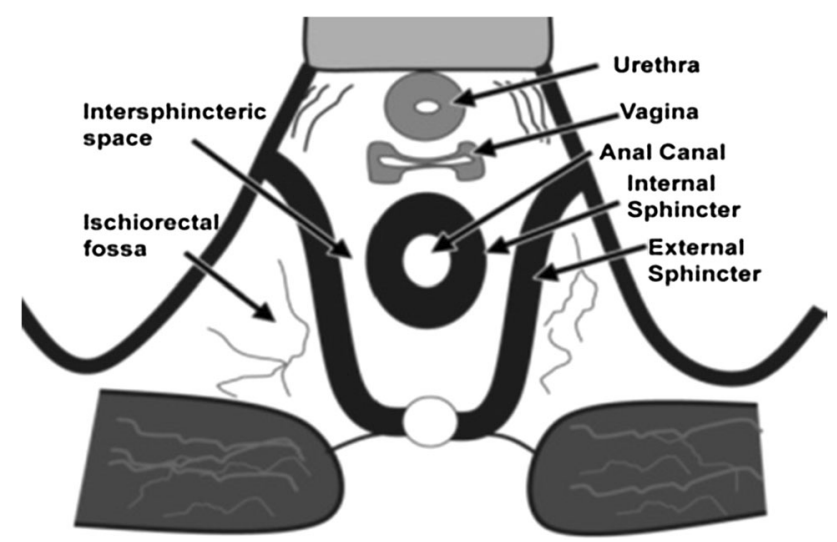

Fig. 3 Diagrammatic representation demonstrating normal female perineal anatomy in axial plane at the level of ischiorectal fossae [4••] 


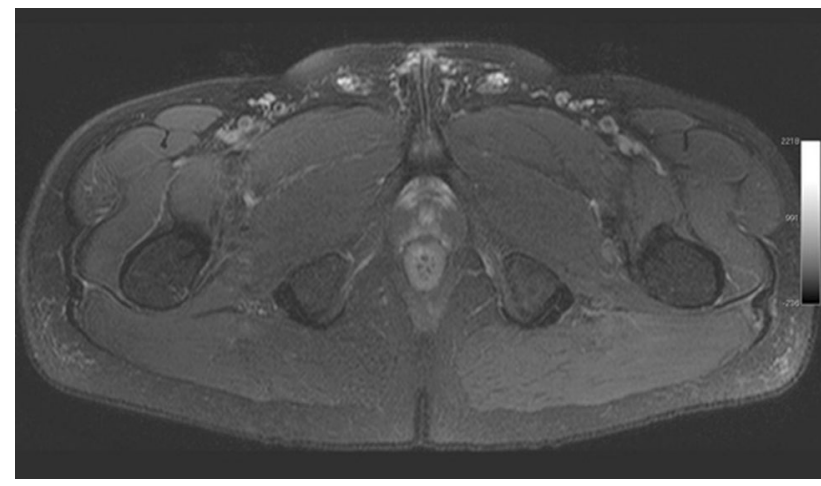

Fig. 4 Axial T2-SPAIR image showing normal anatomy. White arrow external anal sphincter, black arrow internal anal sphincter, blue arrow anal canal submucosa and lumen

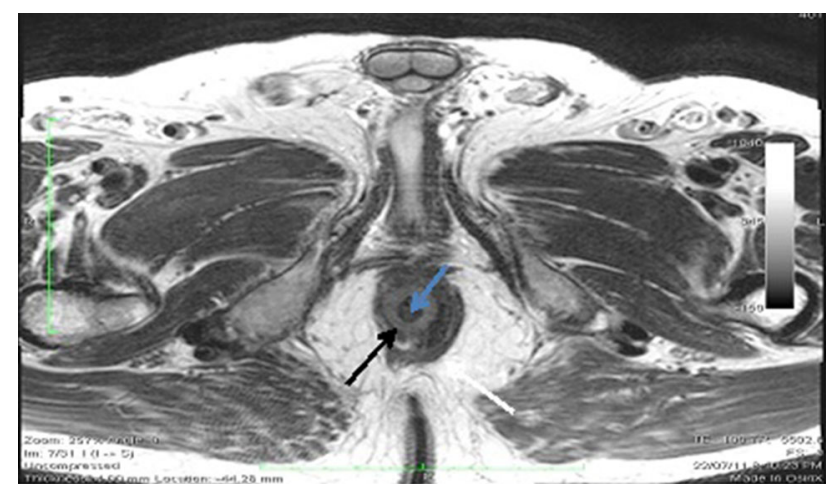

Fig. 5 Axial T2 TSE image showing normal anatomy. White arrow external anal sphincter, black arrow internal anal sphincter, blue arrow anal canal submucosa and lumen

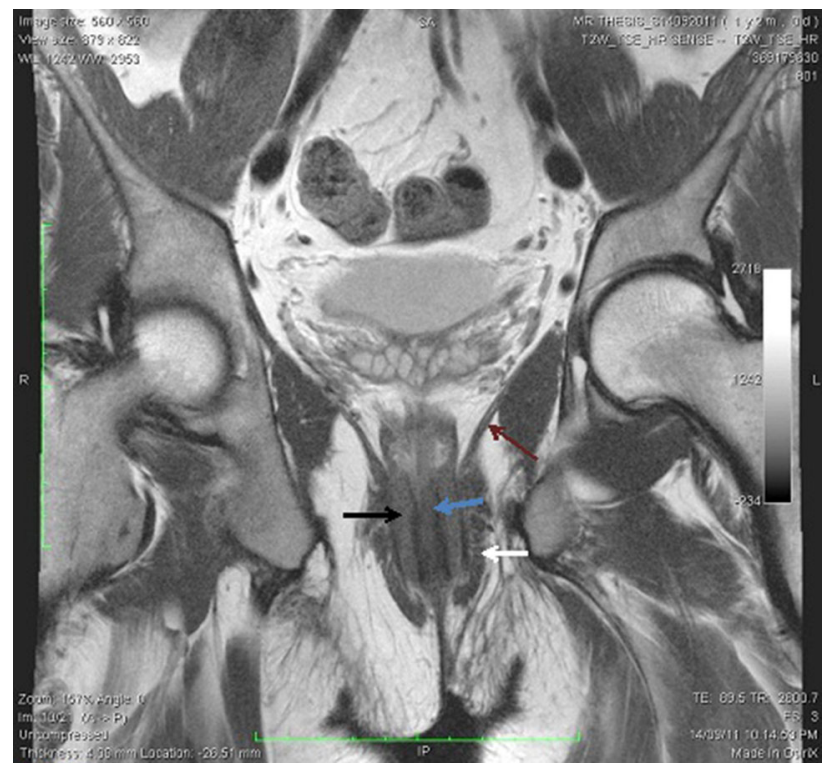

Fig. 6 Coronal T2 TSE image demonstrating normal anatomy. Spin echo images without fat suppression are excellent for demonstrating normal anatomy as can be seen in this image. White arrow external anal sphincter, black arrow internal anal sphincter, blue arrow anal canal submucosa and lumen, red arrow levator ani the intersphincteric space, and an intersphincteric fistula will form when it reaches the skin. Alternatively, infection may pass through both layers of the external sphincter, forming a transsphincteric fistula, and enter the ischiorectal fossa, causing inflammatory changes and abscesses.

However, the cryptoglandular hypothesis cannot explain the formation of fistulas in inflammatory processes such as Crohn's disease and diverticulitis, which result in the development of extrasphincteric fistulas, with a direct communication between the perineum and rectum or other visceral structures such as the vagina, with no involvement of the anal canal.

Fistula Anatomy and Classification

A thorough knowledge of the anatomy of the anal canal and rectum, with the different muscle layers of sphincters and pelvic floor and the associated surrounding spaces, is essential for the classification and understanding of anal fistulas and subsequent decisions on treatment. The predominant classification system is that described by Parks et al. [2•], which classifies the fistula according to the primary tract's relation to the external and internal sphincters and the levator ani muscle. The following are the four categories:

\section{Parks' Classification}

I. Intersphincteric

II. Transsphincteric

III. Suprasphincteric

IV. Extrasphincteric

Superficial fistulas were not included in the original classification as they were considered to have a different etiology.

Intersphincteric fistulas accounted for $45 \%$ of cases in the study of Parks et al. [2•] and represented the most common of the four categories. These fistulas ramify only in the intersphincteric space and do not traverse the external sphincter, which forms a relative barrier to the spread of infection. The track runs along the longitudinal muscle layer between the internal and external sphincters and may reach the perianal skin through or medial to the subcutaneous external sphincter.

In transsphincteric fistulas (30\% of cases in the study), the track passes from the intersphincteric space through the external sphincter into the ischiorectal fossa.

In suprasphincteric fistulas (20\% of cases in the study), the track progresses upward into the intersphincteric space, passes over the top of the puborectalis muscle, and then descends through the levator plate to the ischiorectal fossa and finally to the skin.

The extrasphincteric fistula (5\% of cases in the study) is the only type of fistula whose etiology cannot be 
explained by the cryptoglandular hypothesis. In extrasphincteric fistulas, the track passes from the perineal skin through the ischiorectal fossa and levator muscles and then into the rectum. Thus, this fistula lies completely outside the external sphincter complex. No infection is found in the intersphincteric space, and the anal canal is not involved. When diagnosing this type of fistula, it is important to exclude primary rectal or pelvic diseases, such as Crohn disease, diverticular disease, or carcinoma.

Another widely used classification system is the St. James University Hospital Classification [5••] which classifies the perianal fistulas as follows.

- Grade 1: simple linear intersphincteric fistula

- Grade 2: intersphincteric with abscess or secondary track

- Grade 3: transsphincteric

- Grade 4: transsphincteric with abscess or secondary track in ischiorectal or ischioanal fossa

- Grade 5: supralevator and translevator.

Apart from the primary tract, a fistula can also have secondary tracts or extensions, both vertically and horizontally. A special type of secondary tract is the horseshoe tract, which extends horizontally in the intersphincteric, ischiorectal, or supralevator space, in most cases dorsal to the anal canal.

The level where the primary tract transverses the external sphincter or levator muscle is another important aspect in classifying fistulas into high and low types, as it determines how much of the sphincter mechanism is encompassed by the fistula: if this level is above the level of the dentate line, then the fistula is considered high. The internal opening of an anal fistula is usually situated at the level of the dentate line. When the external opening(s) is situated in the posterior half of the perianal area, the internal opening is usually located in the posterior midline, but when the external opening is anterior, the internal opening is usually situated radially in the same direction (Goodsall's rule) (Figs. 7, 8, 9).

\section{Role of Magnetic Resonance Imaging}

Magnetic resonance imaging (MRI) is a test that uses a magnetic field and pulses of radio-wave energy to image body tissues. MRI machines make use of the fact that body tissue contains lots of water, and hence protons $\left({ }^{1} \mathrm{H}\right.$ nuclei), which get aligned in a large magnetic field. It uses magnetic fields of high strengths and radiofrequency waves to obtain data which are then analyzed by complex algorithms, and finally images are produced which can be used to make a diagnosis. The main advantages of MRI are its

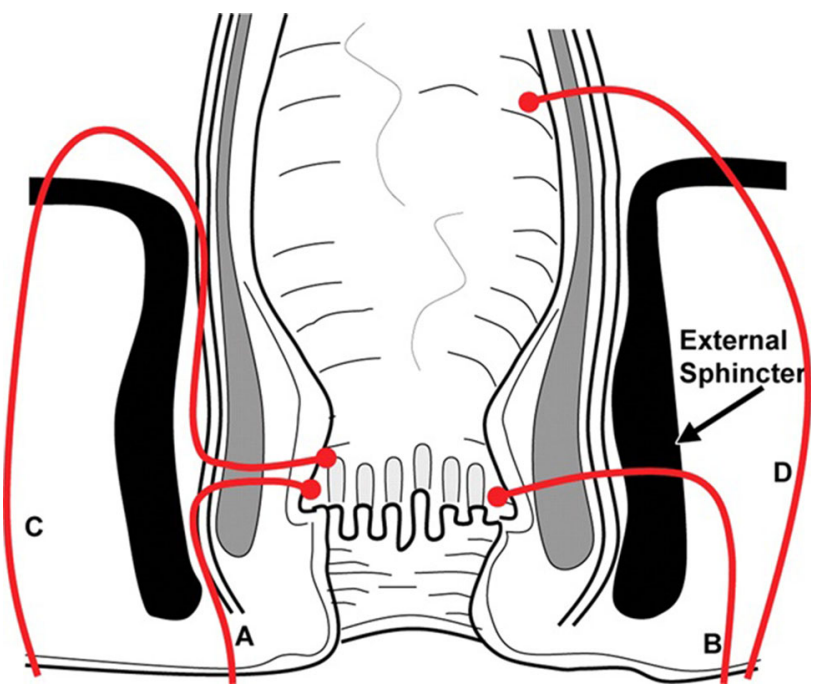

Fig. 7 Diagrammatic representation demonstrating the various types of perianal fistulas as described in the Parks' classification. $A$ Intersphincteric. $B$ Transsphincteric. $C$ Suprasphincteric. $D$ Extrasphincteric. The external sphincter is the keystone of the Parks classification $[4 \bullet \bullet]$

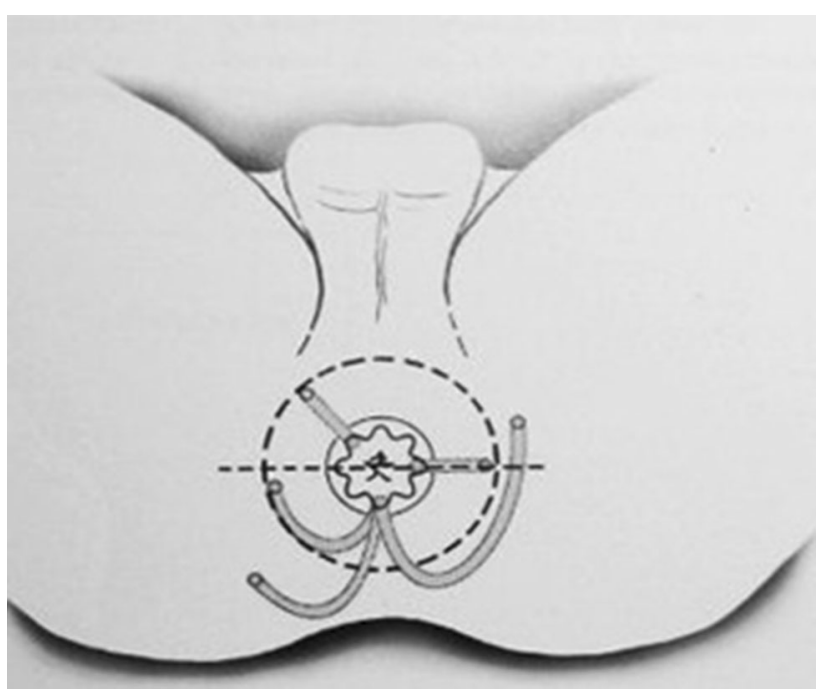

Fig. 8 Figure demonstrating the Goodsall rule-when the external opening $(s)$ is situated in the posterior half of the perianal area, the internal opening is usually located in the posterior midline, but when the external opening is anterior, the internal opening is usually situated radially in the same direction. An exception to the rule is anterior fistulas lying more than $3 \mathrm{~cm}$ from the anus, which may have a curved track (similar to posterior fistulas) that opens into the posterior midline of the anal canal

superior soft-tissue contrast resolution even without use of intravenous contrast and its multiplanar imaging capabilities. The value of MRI in assessing anal fistula was first demonstrated for perianal Crohn's disease [6]. The first studies on cryptoglandular fistula were performed with 


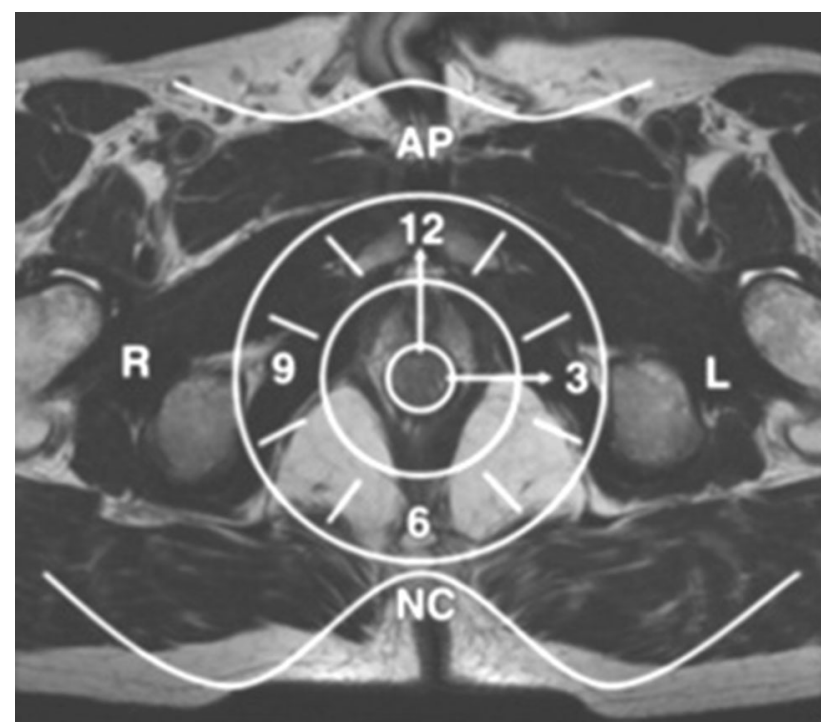

Fig. 9 Anal clock Axial T2-weighted MR image of the male perineum shows which is the surgeon's view of the perianal region when the patient is in the lithotomy position. This schema exactly corresponds to the orientation of axial MR images of the perianal region and can be used to correctly locate anal fistulas with respect to the anal canal $\left[5^{\bullet \bullet}\right]$

body coil MRI [7, 8]. Later comparisons have in some cases demonstrated improved results with an endoanal coil $[9,10]$. Many studies have demonstrated superiority of MRI in the management of perianal fistulas as compared to other imaging modalities (Tables 1, 2, 3; Figs. 10, 11, 12, $13,14,15,16,17,18)$.

The advantages of MRI are

(1) No radiation exposure.

(2) Excellent soft-tissue contrast resolution.

(3) Can easily provide all the required information.

(4) Both functional and anatomical assessment can be carried out at once if required.

(5) Better patient compliance as compared to conventional fistulography and endoanal ultrasound.

Table 1 MR imaging features of perianal fistulas and abscesses

\begin{tabular}{cll}
\hline Condition & Pulse sequence & $\begin{array}{l}\text { Signal intensity appearance } \\
\text { (fistula/edema) }\end{array}$ \\
\hline $\begin{array}{c}\text { Fistula/ } \\
\text { edema }\end{array}$ & T1-weighted & Low/low \\
& T2-weighted & High/high \\
& STIR & High/high \\
& T1-weighted contrast- & Enhancing/low \\
& enhanced & \\
Abscess & T1-weighted & Low \\
& T2-weighted & High \\
& STIR & High \\
& T1-weighted contrast- & Low, with peripheral \\
& enhanced & enhancement \\
\hline
\end{tabular}

Table 2 Comparison of various modalities

\begin{tabular}{|c|c|c|c|}
\hline & $\begin{array}{l}\text { Conventional } \\
\text { fistulography }\end{array}$ & Endoanal USG & MRI \\
\hline $\begin{array}{l}\text { Use of } \\
\text { radiation }\end{array}$ & + & - & - \\
\hline $\begin{array}{l}\text { Ability to } \\
\text { demonstrate } \\
\text { secondary } \\
\text { tracts }\end{array}$ & \pm & \pm & + \\
\hline $\begin{array}{l}\text { Ease of } \\
\text { performing }\end{array}$ & - & - & + \\
\hline Cost & Cheaper & Cheaper & $\begin{array}{l}\text { Costly } \\
\text { investigation, } \\
\text { but cost- } \\
\text { effective in } \\
\text { terms of } \\
\text { information } \\
\text { provided }\end{array}$ \\
\hline Sensitivity & $40-60 \%$ & $\begin{array}{l}70-90 \% \\
\text { Lower for deep } \\
\text { seated } \\
\text { abscesses and } \\
\text { complex } \\
\text { branching } \\
\text { fistulae due to } \\
\text { limited field of } \\
\text { view }\end{array}$ & $90-100 \%$ \\
\hline
\end{tabular}

Table 3 Optimal sequence for evaluation of perianal fistulas as per our study

\begin{tabular}{ll}
\hline Sequence & Slice thickness/slice gap $(\mathrm{mm} / \mathrm{mm})$ \\
\hline Survey/localizer sequence & - \\
T1TSE axial & $4 / 0.4$ \\
T2 TSE axial & $4 / 0.4$ \\
T2 SPAIR-axial & $4 / 0.4$ \\
Sagittal & $3 / 0.3$ \\
Coronal & $3 / 0.3$ \\
\hline
\end{tabular}

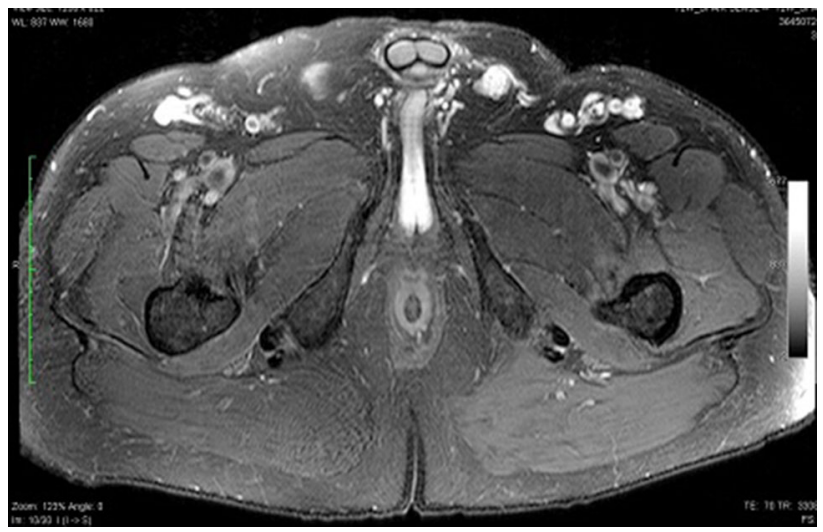

Fig. 10 Axial T2 SPAIR image demonstrating transsphincteric fistula with the fistulous tract seen traversing through both the internal and external sphincters to open at 6 o'clock position 


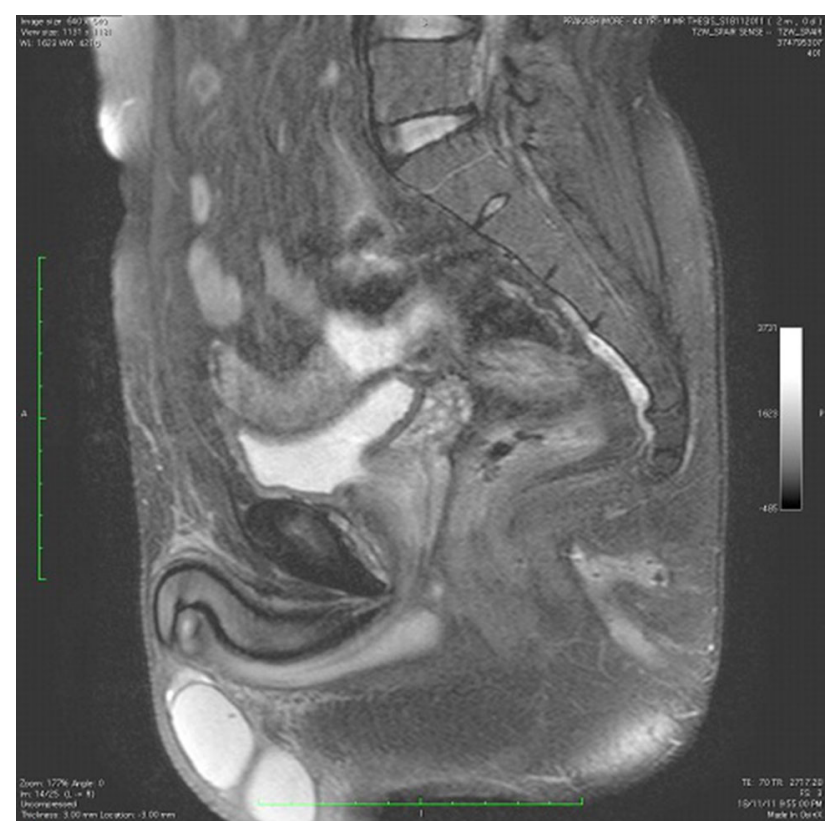

Fig. 11 Sagittal T2 SPAIR image showing a branching fistulous tract

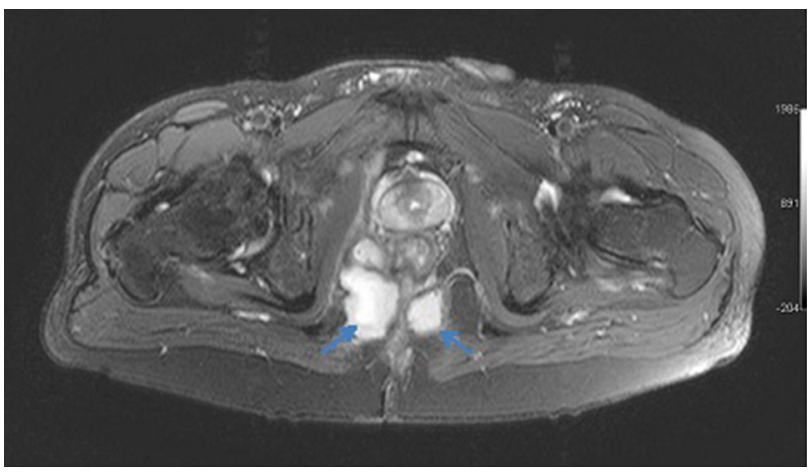

Fig. 12 Axial T2 SPAIR image showing multiple collections in bilateral ischiorectal fossae appearing hyperintense

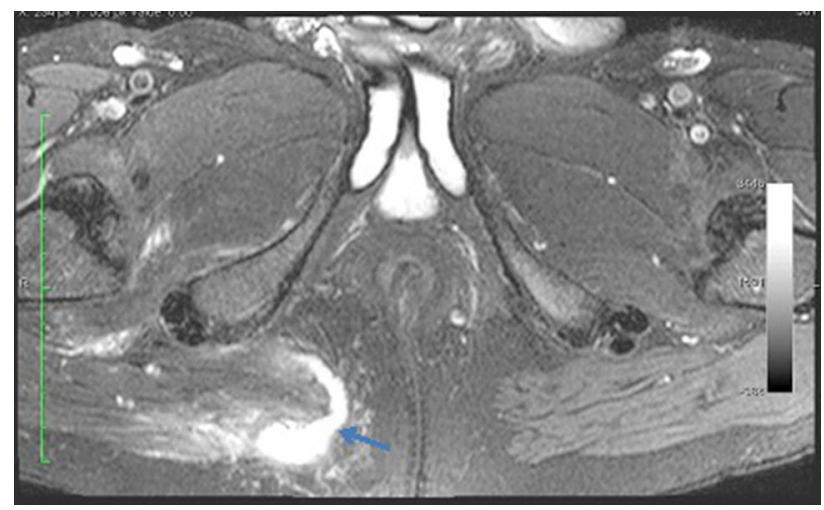

Fig. 13 Axial T2 SPAIR image showing a collection in right gluteal region tracking along the gluteus maximus muscle. It is impossible with conventional imaging to identify findings such as these

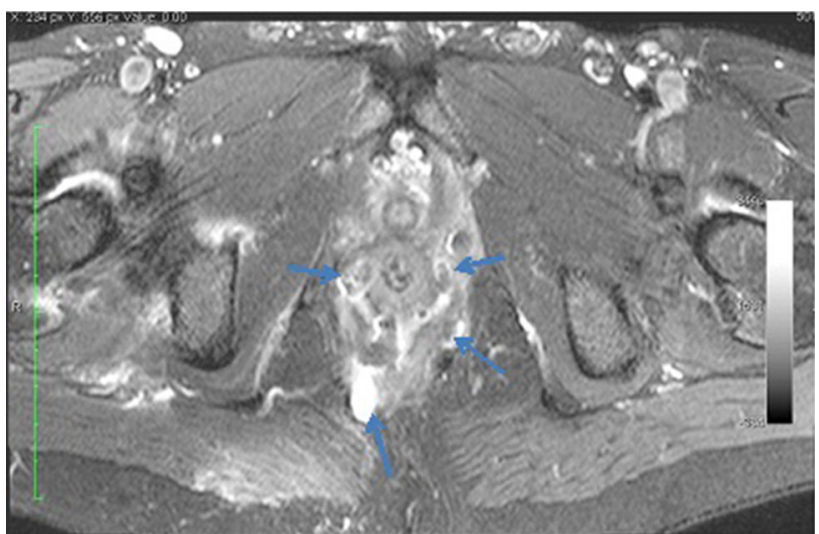

Fig. 14 Axial T2 SPAIR image showing numerous inflammatory collections-located in both the ischiorectal fossae and in intersphincteric plane as well. The external anal sphincter also appears buly with T2 hyperintense signal s/o inflammatory changes (edema)

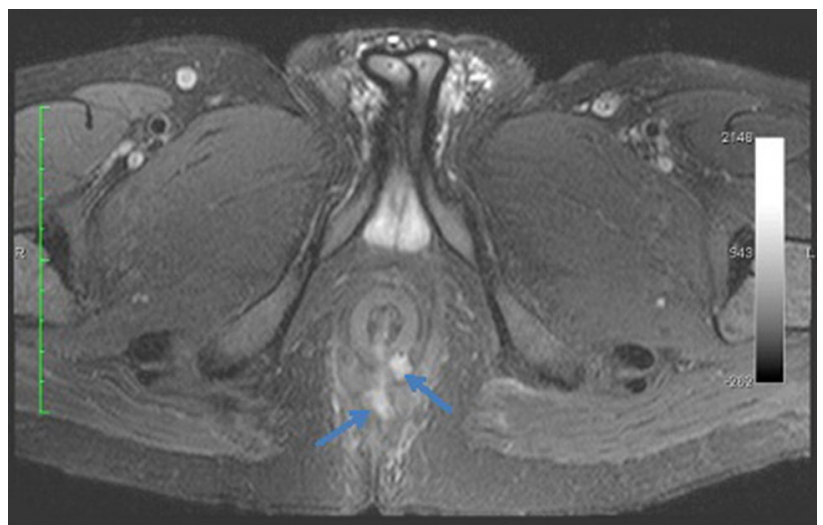

Fig. 15 Axial T2 SPAIR image showing small collections intersphincteric plane and extrasphincteric plane posteriorly

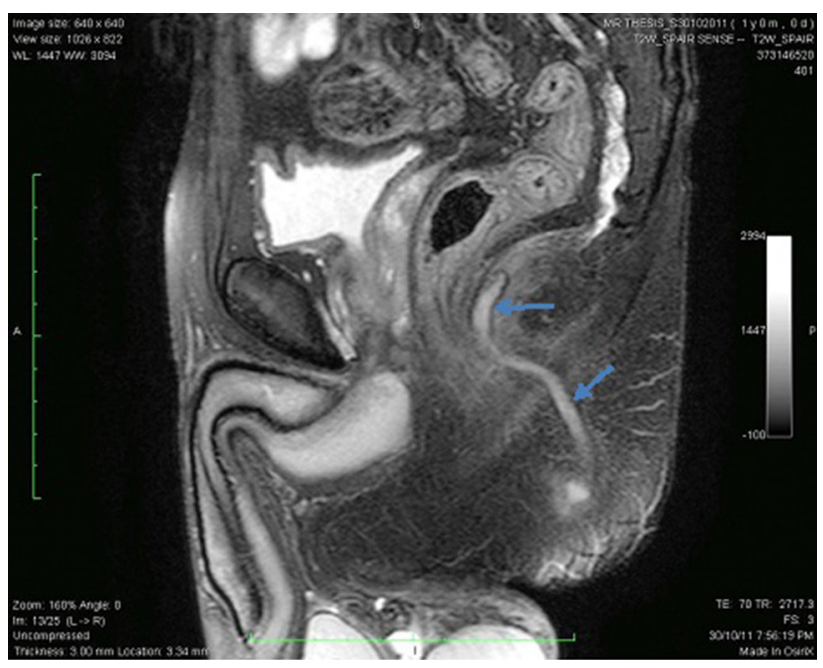

Fig. 16 Sagittal T2 SPAIR image showing a posterior transsphincteric fistula which continues as another tract till just below the levator ani muscles 


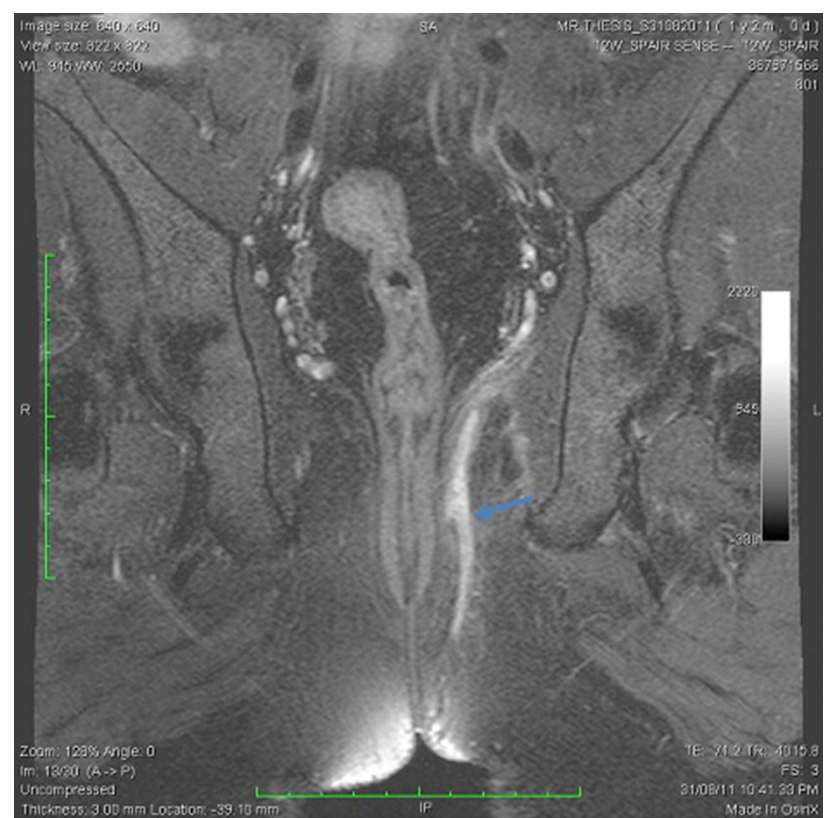

Fig. 17 Coronal T2 SPAIR image showing a transsphincteric fistula coursing just lateral to the external anal sphincter

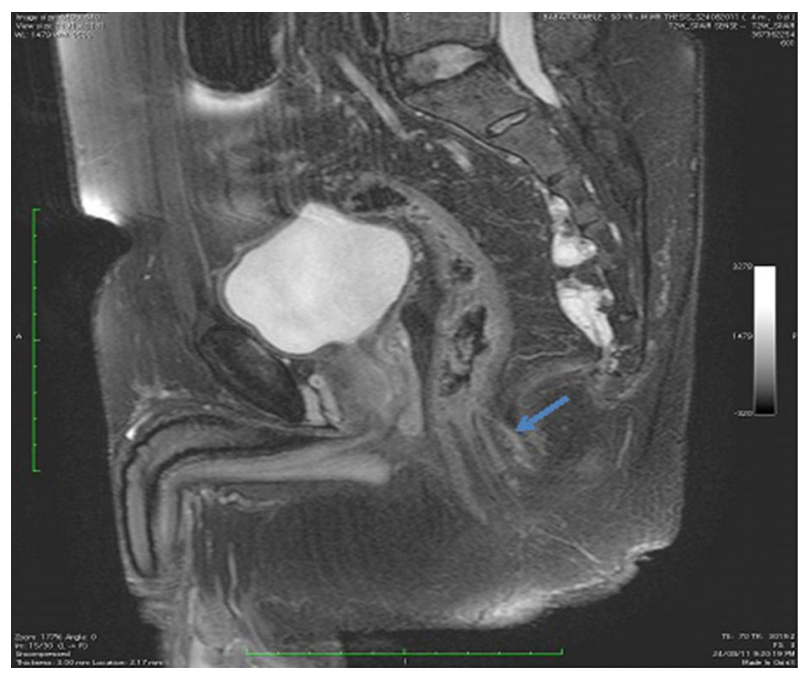

Fig. 18 Sagittal T2 SPAIR image showing an extrasphincteric fistula

The disadvantages are

(1) Takes a longer time

(2) Costly

(3) Lesser availability

(4) Some patients may experience claustrophobia and may not be able to co-operate in the study.

\section{Conclusions}

1. Accuracy of magnetic resonance (MR) imaging in imaging perianal fistulas:
MRI is highly accurate in identifying the fistulous tract, its course, branches, and associated inflammatory collections if any. In a study performed at our centre, it accurately identified the fistulous tract in all the cases which is better than the previously reported sensitivity of $85 \%$ by Maier et al. [11], $91 \%$ by Buchanan et al. [12•], and $94 \%$ by Lunniss et al. [7].

It can accurately demonstrate the relationship of fistulous tract with the external and internal anal sphincter and can, thus, accurately classify the type of fistula.

2. Additional clinical value of preoperative MR imaging: MRI noninvasively offers important information that can reduce surgical complications and postoperative recurrence of the disease. The exact disease burden, deep seated and occult inflammation, tract ramifications can only be accurately demonstrated by MRI. No other imaging modality can as accurately demonstrate these important pathologies as an MRI examination. It must be noted that failure to identify these is the most important cause of persistence of disease and recurrence [13]. The importance of associated findings, their identification by MRI and implications for surgical management, was also highlighted in articles by Spencer et al. [14] and Beets-Tan et al. [15].

As mentioned previously, MRI also accurately classifies the type of perianal fistula by assessing its relationship with the internal and external anal sphincters. This information is particularly valuable in deciding the surgical management and estimating the risk of postoperative incontinence.

Operating a perianal fistula without an MRI would be doing a 'blind' and partial management of the disease. This clearly highlights that the important role of MRI has in the management of perianal inflammatory disease.

In our experience, T2-weighted fat-saturated sequences (i.e., T2 SPAIR) are excellent in the demonstration of perianal fistulas and associated pathology. Thinner sections with minimum inter-slice gap must be used for better spatial resolution. Spin echo sequences, i.e., T1 \& T2 TSE are useful for demonstrating normal anatomy.

The study protocol for optimal imaging on a 3T MRI scanner can be fairly short and time saving without any compromise of the usefulness of the study. In our experience, the following protocol is optimum (Table 3).

The time required for the scan with these sequences is approximately $14-15 \mathrm{~min}$ only. The protocol is well suited both for demonstrating the pathology and for reducing scan time, which in turn improves patient co-operation as well improves patient throughput in a busy department. 
To summarize, MRI exquisitely depicts the perianal anatomy and shows the fistulous tracks and their associated ramifications and abscesses. It thus provides an excellent preoperative understanding of the disease, enabling selection of the most appropriate surgical treatment and, therefore, minimizing all chances of recurrence. It should be considered the investigation of choice for evaluation of perianal fistulas.

\section{Compliance with Ethics Guidelines}

Conflict of Interest Anagha R. Joshi is a section editor for Current Radiology Reports. Sukhvinder G. Siledar declares no potential conflicts of interest.

Human and Animal Rights and Informed Consent This article does not contain any studies with human or animal subjects performed by any of the authors.

\section{References}

References of particular interest have been highlighted as:

- Of importance

-• Of major importance

1. Goodsall DH, Ernest Miles W. Classic articles in colonic and rectal surgery. Diseases of the anus and rectum. Dis Colon Rectum. 1982;25(3):262-78.

2. Parks AG, Gordon PH, Hardcastle JD. A classification of fistula-in-ano. Br J Surg. 1976;63(1):1-12. Article describing the widely used Parks classification of Perianal fistulas.

3. Kuijpers JH, Schulpen T, Buyck B. The Seton method for the treatment of perianal fistula located outside of the sphincter. Ned Tijdschr Geneeskd. 1985;129(20):945-7.

4. - de Miguel Criado J, del Salto LG, Rivas PF, del Hoyo LF, Velasco LG, de las Vacas MI, et al. MR imaging evaluation of perianal fistulas: spectrum of imaging features. Radiographics.
2012;32(1):175-94. Excellent article describing pathology, MR imaging protocol \& role of MRI in management of perianal fistulas.

5. • Morris J, Spencer JA, Ambrose NS. MR imaging classification of perianal fistulas and its implications for patient management. Radiographics. 2000;20(3):623-35; discussion 35-7. Article evaluating the importance of preoperative MRI imaging of perianal fistulas.

6. Koelbel G, Schmiedl U, Majer MC, Weber P, Jenss H, Kueper K, et al. Diagnosis of fistulae and sinus tracts in patients with Crohn disease: value of MR imaging. AJR. 1989;152(5):999-1003.

7. Lunniss PJ, Barker PG, Sultan AH, Armstrong P, Reznek RH, Bartram CI, et al. Magnetic resonance imaging of fistula-in-ano. Dis Colon Rectum. 1994;37(7):708-18.

8. Myhr GE, Myrvold HE, Nilsen G, Thoresen JE, Rinck PA. Perianal fistulas: use of MR imaging for diagnosis. Radiology. 1994;191(2):545-9.

9. Hussain SM, Stoker J, Schouten WR, Hop WC, Lameris JS. Fistula in ano: endoanal sonography versus endoanal MR imaging in classification. Radiology. 1996;200(2):475-81.

10. Zbar AP, de Souza NM, Puni R, Kmiot WA. Comparison of endoanal magnetic resonance imaging with surgical findings in perirectal sepsis. Br J Surg. 1998;85(1):111-4.

11. Maier AG, Funovics MA, Kreuzer SH, Herbst F, Wunderlich M, Teleky BK, et al. Evaluation of perianal sepsis: comparison of anal endosonography and magnetic resonance imaging. JMRI. 2001;14(3):254-60.

12. - Buchanan GN, Halligan S, Bartram CI, Williams AB, Tarroni D, Cohen CR. Clinical examination, endosonography, and MR imaging in preoperative assessment of fistula in ano: comparison with outcome-based reference standard. Radiology. 2004;233(3): 674-81. A study of 104 patients comparing Endoanal USG with MRI.

13. Lilius HG. Fistula-in-ano, an investigation of human foetal anal ducts and intramuscular glands and a clinical study of 150 patients. Acta Chir Scand Suppl. 1968;383:7-88.

14. Spencer JA, Chapple K, Wilson D, Ward J, Windsor AC, Ambrose NS. Outcome after surgery for perianal fistula: predictive value of MR imaging. AJR. 1998;171(2):403-6.

15. Beets-Tan RG, Beets GL, van der Hoop AG, Kessels AG, Vliegen RF, Baeten CG, et al. Preoperative MR imaging of anal fistulas: does it really help the surgeon? Radiology. 2001; 218(1):75-84. 